\title{
浅谈林业苗围移植苗及大苗的培育技术
}

高宗林

凌源市三十家子国合造林站

DOI:10.32629/as.v1i4.1488

[摘 要] 文章主要介绍了苗围移植苗及大苗的培育技术,并对移植中的注意事项、前期准备和后期管理等工作内容进行详细 阐述,希望对我国林木种苗的发展提供帮助。

[关键词] 苗围; 移植苗及大苗; 培育技术

移植技术的应用有助于增大苗木的成活率, 培育良好的 树种。在我国林业种苗发展过程中, 通过移植技术的应用可 以提升苗木产量, 培育出更多高质量、高成活率的苗木, 进而 为我国林业建设创造更多有利条件。

\section{1 幼苗和芽苗移植技术}

1.1 苗木移植的作用和种类

幼苗移植和芽苗移植是苗木移植中较为主要的两个部分, 通过移植技术栽种的苗木能够有效增加成活率。一般在实际 操作中, 会通过移植或者截断主根的方式, 来加大苗木侧根和 根须的生长率, 降低苗木茎根的比值, 阻止苗木高生长。

\section{2 移植方法和注意事项}

(1) 移植方法

目前最常使用的苗木移植方法有两种, 即人工移植和移植 机移植。移植机移植相对较为简单, 只需设定好移植间距等, 通过机械操作直接进行移植。人工移植一般是穴植和沟植。对 苗木而言, 还分裸根移植和带土球移植两种。沟植法是按照行 距和株距进行场地挖掘和栽植, 不过在移植完成后, 要确保覆 盖图的密实度, 以免根系裸露在外影响苗木正常生长。穴植法 同沟植法的栽植处理方式相同, 不过在苗木选择上具有一定 的限制性。通常会将该方法用在大型苗木移植作业中。

(2) 移植技术

在移植过程中, 不管采用哪种移植方式, 都需要关注以 下几点: 其一, 要根据原土印来确定移植深度, 要比其浅 2 厘 米左右。这样的做法是为了保证苗木根系的正常舒展, 防止 窝根问题的产生。具体操作方式为, 将苗木放入到沟或穴中 后, 回填土到整体容量的 8 成左右, 之后将苗木提起一部分 距离, 让根系自然下垂, 之后再开始填土作业, 并保证其高于 地面两厘米距离, 踩实。其二, 在移植带土苗木时, 先要检查 苗木的质量, 确保其完好后再开始移植。同时在移植过程中, 应采取保护措施预防顶芽损伤。一般对于带土的苗木都是采 用截干苗移植法。

\section{2 幼苗和芽苗移植前的相关技术}

2.1 准备工作

（1）根据苗木生长习性, 选择合适的移植场所, 并合理规 划移植作业中需要的人力、物力资源, 保证移植的顺利进行。

(2) 苗木准备
在苗木移植前, 要确保移植苗木的随时性, 随时运送、修 剪和栽植。不能立即进行栽植的苗木也要做好相应的假植保 护措施, 并确保根系有充足的水分供给。

(3) 苗木分级

苗木分级处理是移植前较为重要的工作, 可以将同种规 格形态的苗木统一移植, 保证苗木的生长的均匀性, 减少分 化的产生。同时分级移植对于后期销售以及苗围管理也有着 一定便利。不过在分级过程中, 要对苗木所处环境以及根系 水分情况实行合理管控, 避免在阳光直射、干燥的地方进行 苗木的分级和修剪, 降低苗木成活率。

\section{2 移植用苗年龄的确定}

移植工作的开展需要根据苗木的年龄确定, 这样才能保 证移植后苗木的正常生长, 降低移植成本。如果移植的苗木 年龄较短, 不仅会增加费用支出, 还无法保证成活; 如果苗木 年龄较大, 其根系相对较粗, 移植后缓苗期较长, 也无法达到 移植效果。因此, 要结合树种合理确定用苗年龄, 保证其成活 率。一般速生树种当其幼苗高达 10 厘米左右时即可实施移 植作业, 且当年移植, 当年就可以出围; 而对于生长较快的阔 叶和部分针叶树种来说, 一年生播种苗即可移植, 如落叶松 和侧柏等; 生长较慢的树种则需在栽植地生长两年后方可移 植, 如红松、冷杉。

\section{3 移植时间}

通常情况下, 苗木的移植会选在休眠期内, 也就是春季 时, 这样能够更好的保证苗木成活率。在春季实施移植作业 时遵循宜早不宜晚的原则, 即刚开始解冻后即可开始移植, 这样苗木的根系中会存在较多的水分和养料, 确保移植后苗 木的正常生长, 提高成活率。在移植过程中, 要根据树种不同 的发芽时间制定移植顺序, 便于后期销售。春季移植对于冬 季较为寒冷干旱的区域来说, 如北方, 有着较好的效果, 在移 植顺序的确定上, 也多是以针叶树、落叶树、常绿阔叶树的 顺序为主。

此外, 秋季和雨季也适合苗木的移植工作。其中秋季移植 较为适合湿润度较高的地区, 像一些沿海城市, 这时的苗木根 系还处在较为活跃的状态下, 移植后能够快速的恢复根系的 生命力, 保证成活率。在秋季移植中, 也要尽早进行, 以免影响 移植效果。雨季移植大多比较适合一些常绿树种, 其移植时间 
需根据区域特征的不同而有所变动。像南方较为多雨的城市, 苗木移植可以在梅雨初期进行。且移植时间要定在清晨或傍 晚, 减少苗木根系的暴晒, 保护士壤结构, 确保其成活率。

\section{4 移植密度}

移植密度的确定需要综合考虑所方面因素, 如苗木的生 长速度、规格、年龄、作业方式、土壤条件等等。在床式作 业中, 针叶树苗株的株距和行距分别控制在 15 和 30 厘米左 右; 阔叶树苗木的株距和行距则要保证在 25 和 40 厘米以内; 针、阔叶树树种的株距会根据实际情况进行合理选择, 且该 类苗木的移植形式以正方形或矩形为主, 株距和行距不会超 过 50、80、100、120 厘米这四个范围。

\section{3 移植}

现阶段人工移植是苗木移植中采用的主要方式, 主要包 括了沟植、穴植和孔植三种:

\section{1 沟植}

沟植较为适用在小苗移植中, 利用犁等工具按照规定的 行距实施开沟作业, 开沟深度要大于苗木的根系长度, 之后 按顺序将苗木栽植在沟内, 开展填土、提苗、踩实工作。

\section{2 穴植}

穴植适用在大型苗木移植作业中, 且最好是带土苗木, 以确保其成活率。之后再按照行距进行定点挖穴, 栽植、封 土、踩实。

\section{3 孔植}

孔植适合主根较长, 侧根短的小苗移植。在具体操作中, 先利用移植铲做好扎缝, 然后将苗木放入缝中, 并向上提, 以 保证根系的舒展, 最后挤压土壤使其密实。

通过上面的分析可以看出, 不管使用哪种移植方法, 都 应该保证苗木的舒展、端直以及深浅适当的效果, 并在移植 完成后, 进行适量浇水湿润, 确保根土的密接。同时在移植过 程中, 还需对苗木做好保护措施, 避免外界环境的影响, 导致 苗木干旱。

\section{4 抚育管理}

4.1 中耕除草

同播种苗相比, 中耕除草的次数会随着时间的推移而逐 渐减少, 如第一年中耕 6 次左右, 第二年可能就只有 4 次, 第 三年会更少, 不过中耕除草的深度要比播种苗深, 这样才能 为苗木提供一个养分充足的生长环境。中耕除草的深度可以 达到 15 米左右。

\section{2 主干和树冠的修整}

主干高度和直径的修整需要根据苗木的用途实行合理 规划。一般用作绿化装饰的苗木, 其主干高度不会超过 4 米; 而具有防护林功效的苗木, 其主干只有 2 米左右。对于公园 绿化中栽植的苗木其主干高度就需要根据装饰效果进行合 理设定, 并没有准确的定义。另外, 在主干修整中, 如果发现 其存在不直的苗木, 可以实施截干处理, 或者去除顶芽来抑
制其高生长, 以满足苗木的用途。

树冠的整形也会结合用途进行修剪,一般行道树冠会以 自然形和人工伞状冠形为主, 观赏类的树冠则会以扇形、杯 形为主。最常用的整形方法是对枝叶和枝条进行修剪。树枝 修剪主要是为了抑制枝条的生长, 以冠幅与实际要求相符。 不过在主干上实行枝条修剪中, 针叶树或者速生树种对于修 剪技术的要求相对较高, 且需要逐层修剪, 以确保整体效果, 而阔叶类树种则相对较为简单。在修剪时间的确定上, 一般 会定在秋季落叶后或者春季发芽前。

\section{3 灌溉、追肥和病虫害管理}

在移植后, 先进行灌溉, 来保证苗木的水分充足, 之后再 开始松土, 提升土壤透气性, 并实施追肥, 为苗木生长提供充 足养分。而病虫害作为苗木生长中较常出现且危害性较大的 问题, 需要按照相关规定要求开展合理的防治作业, 保证苗 木的成活率。

\section{5 大苗培育技术}

在苗固中进行大苗培育时, 不同的树种类型有着不同的 要求差异。如阔叶树种要保证树干笔直、主干和树高分别控 制在 4 米和 7 米左右; 常绿针叶树则要求枝条分布均匀, 树 冠和冠形良好。栽植成活后的大苗要实行整形修剪, 通过养 干疏枝对苗干和苗冠予以控制和调整。

5.1 养干、疏枝

对于树干不直、长势不旺的阔叶树, 需要在春季发芽前 先完成平茬处理, 待萌生条长到 30 厘米长度时, 对其中较为 健壮的枝条进行养干, 确保主干通直效果。对于徒长枝、过 密枝、交叉枝、病虫枝, 要从基部剪去, 促使苗冠均衡发展。

5.2 侧枝伸展方向的调整

在侧枝调整中, 要对枝芽予以调整, 枝芽在哪个方向, 侧 枝将会向着那个方向延伸。

\section{3 冠高比}

耐阴树种的冠高比应大些, 一般冠高比占总体的三分之 二或者四分之三左右, 并随着苗木的生长, 对其下部开展枝 条修剪工作, 且在主干达到规定高度后停止修剪, 扩大苗冠, 确保苗木有充足的养分供应。

\section{6 结束语}

综上所述, 在苗木移植和大苗培育中需要关注的内容较 多, 工作人员需要结合实际情况, 制定合理的移植计划, 以此 保证苗木的正常生长, 提高我国林业种苗水平。

\section{[参考文献]}

[1]连建宝.林业苗围管理中存在的问题及解决对策[J]. 农业开发与装备,2018,(01):42+53.

[2]杨孝柳,唐启发。绿化大苗培育苗木移植技术[J].农技 服务,2012,29(04):446-447.

[3]郭蓉. 林业苗围移植苗及大苗的培育技术分析[J]. 种 子科技,2018,36(12):56+58. 